\title{
Postpartum Depression in a Caretaking Grandmother: Case Report
}

Valerie D. Raskin, M.D.

Michael Reese Hospital and Medical Center, Chicago, Illinois

Follow this and additional works at: https://jdc.jefferson.edu/jeffjpsychiatry

Part of the Psychiatry Commons

Let us know how access to this document benefits you

\section{Recommended Citation}

Raskin, M.D., Valerie D. (1990) "Postpartum Depression in a Caretaking Grandmother: Case Report," Jefferson Journal of Psychiatry. Vol. 8 : Iss. 1 , Article 6.

DOI: https://doi.org/10.29046/JJP.008.1.014

Available at: https://jdc.jefferson.edu/jeffjpsychiatry/vol8/iss1/6

This Article is brought to you for free and open access by the Jefferson Digital Commons. The Jefferson Digital Commons is a service of Thomas Jefferson University's Center for Teaching and Learning (CTL). The Commons is a showcase for Jefferson books and journals, peer-reviewed scholarly publications, unique historical collections from the University archives, and teaching tools. The Jefferson Digital Commons allows researchers and interested readers anywhere in the world to learn about and keep up to date with Jefferson scholarship. This article has been accepted for inclusion in Jefferson Journal of Psychiatry by an authorized administrator of the Jefferson Digital Commons. For more information, please contact: JeffersonDigitalCommons@jefferson.edu. 


\title{
Postpartum Depression in a Caretaking Grandmother: Case Report
}

\author{
Valerie D. Raskin, M.D.
}

Postpartum depression has only recently been understood to affect individuals other than the biological mother (1). In such cases, postpartum depression has been attributed to the enormous psychological and social stress of the caretaking role, with its demands to nurture in the face of what may be the sense of having been insufficiently nurtured oneself (2). A growing number of grandparents, especially maternal grandmothers, are being asked to serve as primary caretakers for their grandchildren, due to circumstances which include adolescent childbearing, single parent families and substance abuse. A case report of a new grandmother with significant caretaking functions who developed major depression one month after the birth of her grandson will be discussed. It will be argued that a combination of hormonal, psychodynamic and social factors contributed to the development of what can best be conceptualized as postpartum depression.

While the psychological impact of parenting one's grandchildren has received little attention, the literature on grandmotherhood in general will be briefly reviewed in this context prior to the case material. Intergenerational conflict over caretaking functions has been attributed to the grandmother's reluctance to relinquish the role of mother; she is seen as undermining her daughter's attempts to mother her children herself (3). The alternative to what has been termed the "intrusive "busybody" " stereotype (4) is the surrogate parent, a grandparenting style held exclusively by women, often reluctantly (5). Cohler and Gruenbaum argue that the resentment grandmothers feel at the expectations of their daughters for advice and assistance with childcare is underrecognized (4).

Intergenerational conflict around issues of caretaking may be especially common between grandmothers and adolescent mothers. The prospect of grandmotherhood for mothers of pregnant adolescents is characteristically anticipated with more distress than is often conceded (6). Smith notes that confusion due to overlapping maternal and grandmaternal roles exacerbates normal developmental conflict around issues of autonomy in adolescence. These "young" grandmothers may be anticipating the "relief from obligations" commonly experienced by grandmothers in our culture (7), but instead find themselves forced to postpone plans for professional or personal development. It may 
be significant that the current cohort of caretaking grandmothers were permitted considerably less reproductive freedom than are their daughters.

\section{CASE REPORT}

Minor changes have been made in the following case report to protect confidentiality. The patient's daughter was evaluated and found to be without major affective or psychotic illness, although alcohol and cannabis abuse were likely diagnoses.

Mrs. D. is a 43 year old white married cashier, mother of 3, who presented seeking help for "nerve wracking problems with my daughter." The precipitant to her visit was an episode in which she hit her 21-year-old daughter J. upon finding her intoxicated shortly after Mrs. D's nine month old grandson had been hospitalized overnight for fever. Although Mrs. D felt that her daughter's behavior proved that "partying means more to her than her baby," she perceived herself to be "overreacting."

She reported feeling pent-up rage at her daughter, along with persistent dysphoria, difficulty concentrating, anorexia, insomnia and frequent crying spells. The symptoms began one month after the birth of her grandson, and DSM-III-R criteria for major depression were met. Mrs. D. reported a single previous non-postpartum depressive episode, during which she made a suicide attempt which resulted in her family doctor "telling my husband he should help me more around the house," a prescription to which she attributed the resolution of that episode. Her medical history was remarkable for osteoporosis, for which she received depot progesterone injections.

Mrs. D.'s daughter J., unmarried and unemployed, resumed living with her parents after announcing her pregnancy "when it was too late to do anything." Mrs. D. has significant responsibility for caring for her grandson, including providing both financial support and practical assistance with feeding, bathing and changing the baby. Mr. D., disabled, performs few household chores, and Mrs. D. feels that he undermines her authority with J., who "has her dad wrapped around her little finger."

Mrs. D. was born to a single, alcoholic mother who "used to say she wished somebody would take me until I was out of diapers." Her biologic father is unknown to her. Her mother died several years ago, and was buried in an unmarked grave (the absence of a marker was attributed to its cost). Mrs. D. stated "I see a lot of my mother in my daughter, always being irresponsible."

For a period of eight months, Mrs. D. was treated with supportive psychotherapy, with resolution of the depressive episode within three months. She stopped a tricyclic antidepressant prior to a full therapeutic trial due to side effects, and declined another agent due to improvement.

In the course of the therapy, she recalled having shut off anger toward her mother since her death. As she acknowledged ambivalence about her mother, her rage toward her daughter diminished, and she recalled repeatedly waking alone at night as a child after her mother had gone to a bar. She began to see her daughter's mothering as suboptimal, but not neglectful or abusive. She made arrangements to have a headstone placed at her mother's grave. She found her husband ready to assist with limited requests for household help, and learned that discussing approaches to J. in advance reduced disagreement between them. Conflict at home abated, and she affirmed "if I made it, I guess he (her grandson) can too." Her daughter and grandson moved next door, and Mrs. D. provides considerable yet reduced caretaking. 


\section{DISCUSSION}

The caretaking role has been implicated in the etiology of postpartum depression in new mothers, as efforts to link neuroendocrine factors (other than genetic predisposition to affective disorders) have gone largely unrewarded (8). The psychological adaptation to motherhood is thought to be negatively affected by social stress and poor social support, in particular, lack of assistance from one's husband (9). Intrapsychic phenomena including ambivalent maternal identification (10) and re-emergence of “inadequate solutions of the past," (11), stimulated by the context of mother-infant interaction (4) have also been considered etiologic.

Unlike the only previous case report of postpartum depression in a grandmother (1), specific psychodynamic information is available and the nature of the grandmothering role is known. Mrs. D. identified strongly with her grandson, projecting onto him the image of being victimized by his alcoholic, irresponsible mother. Her rage at her daughter's defective mothering is a displacement of her feelings toward her own mother, denied due to pathologic mourning.

It has been argued that the occurrence of postpartum depression in individuals who are not the biologic mother "supports the conclusion that postpartum reactions are primarily psychogenic" (1). However, a grandmother (or father) who shares significant caretaking functions with the new mother also shares her socially mediated psychiatric vulnerability. This patient previously suffered major depression at a time when she felt overburdened by the demands of her role in the household. In this case, the grandmother's provision of social support to her daughter may have served to buffer the psychological consequences to the new mother at the cost of the grandmother's own well-being.

Biologic factors may also have contributed to Mrs. D.'s depression. Family history of alcoholism has been linked to increased risk of affective disorder (12), and progesterone is an apparent biologic risk factor for depression (13). This case material best supports a biopsychosocial etiology for Mrs. D.'s postpartum depression.

The model of postpartum depression may have therapeutic as well as descriptive value. Conceptualizing a new grandmother's depression as postpartum highlights the crucial role that context plays in the development of certain affective disorders. Clinicians who treat postpartum disorders must reject cultural stereotypes about the universal joys of motherhood in favor of recognizing the complex and often ambivalent emotional responses to caring for infants. This conceptualization may further assist clinicians in recognizing stereotyped notions about grandmotherhood, both in the countertransference and in the environment in which such patients live.

Finally, recognition of the postpartum period as one of psychiatric vulnerability for grandmothers as well as for mothers and fathers may stimulate additional research into identifying factors which increase or protect against 
distress. It is hypothesized that high risk grandmothers include those who assume significant caretaking functions.

\section{REFERENCES}

1. Asch S, Rubin L: Postpartum reactions: Some unrecognized variations. Am J Psychiatry 131:870-874, 1974

2. Gurwitt A: On becoming a family man. Psychoanal Inq 8:261-279, 1988

3. Dell PF, Applebaum AS: Trigenerational enmeshment: Unresolved ties of singleparents to family of origin. Am J Orthopsychiatry 47:52-59, 1979

4. Cohler B, Gruenbaum H: Mothers, Grandmothers and Daughters: Personality and Child-Care in Three-Generational Families. New York: John Wiley \& Sons, 1988

5. Neugarten BL, Weinstein KL: The changing American grandparent. J Marriage Fam 26:199-204, 1964

6. Smith EW: Transition to the role of grandmother as studied with mothers of pregnant adolescents, in American Nurses Association Clinical Sessions. pp 140148, New York: Appleton-Century-Crofts, 1971

7. Rosow I: Socialization to Old Age. Berkeley: University of California Press, 1974

8. Hopkins J, Marcus M, Campbell S: Postpartum depression: A critical review. Psychol Bull 95:498-515, 1984

9. Paykel E, Emms E, Fletcher J, Rassaby E: Life events and social support in puerperal depression. Br J Psychiatry 136:339-346, 1980

10. Melges F: Postpartum Psychiatric Syndromes. Psychosom Med 30:95-108, 1968

11. Bibring G: Some considerations of the psychological process in pregnancy. Psychoanal Study Child 14:113-121, 1959

12. Cadoret R, Winokur G: Depression in alcoholism. Ann NY Acad Sci 233:34-39, 1972

13. Halbreich U, Endicott J, Goldstein S, et al: Premenstrual changes and changes in gonadal hormones. Acta Psychiatr Scand 74:576-586, 1986 